DOI 10.15393/j9.art.2017.4201

УДК 821.161.1.09“18”

\title{
Екатерина Александровна Михеичева
}

Орловский государственный университет им. И. С. Тургенева

(Орел, Российская Федерачия)

inoliterat@mail.ru

\section{МОТИВ ВОСКРЕШЕНИЯ В ТВОРЧЕСТВЕ ПЕОНИДА АНДРЕЕВА}

Аннотация. Данная статья посвящена проблеме воскрешения, получившей широкое распространение в философии и в литературе Серебряного века. Опираясь на Евангельский текст, русские философы Н. Федоров, B. Соловьев процесс воскрешения связывают с усовершенствованием природы и сплочением человечества. В ином ключе последствия возвращения из небытия в реальный мир видит Леонид Андреев. Попытки воскрешения (Василий Фивейский) и само воскрешение (Елеазар) представлены им как трагедия личности. Фивейскому, поверившему в собственное избранничество, не удается повторить подвиг Христа - воскресить Семена Мосягина, и это становится причиной сумасшествия и смерти героя. Воскресение Лазаря, видевшего смерть и ее преодолевшего, представлено Андреевым как трагедия и самого воскресшего, и всех тех, с кем он соприкоснулся после возвращения из небытия. Понимание конечности времени помогает человеку сохранять свежесть чувства и мысли, жить в рамках морально-нравственных категорий, наслаждаться каждым мгновением земной жизни.

Ключевые слова: философия, литература, Евангелие, Леонид Андреев, мотив воскрешения, время, пространство, трагедия

$\Pi$ опытка остановить время, справиться с уничтожением памяти, преодолеть веками установленный порядок мира, согласно которому человек рождается и умирает, характерна для русских мыслителей конца XIX - начала XX вв. У истоков идеи «воскрешения» стоит философ Николай Федорович Федоров, оказавший громадное воздействие на развитие философской мысли в России. Обоснование этой идеи Федоров находит в Евангелии, одна из заповедей которого - «мертвых воскрешайте» (Мф. 10:8) - воспринимается им как призыв к действию. Сам процесс воскрешения возможен благодаря жертве Христа, который вокрес к вечной жизни. «Воскрешение Лазаря есть прежде всего величайший нравственный подвиг, 
проявление безграничной любви и мужества до самоотвержения, ибо возвратить жизнь Лазарю Христос мог, только положив жизнь собственную», - так оценивает «мессианское дело Христа» русский философ $[13,396]$.

«Философия общего дела» Федорова строится на идее, что человек такой же творец, как и Творец, и он призван усовершенствовать этот мир. Путь к совершенствованию - сплочение Человечества, регуляция природы, погружение в «толщу рода», присущее каждому чувство сопричастности - и только на этом пути можно достичь Бессмертия. Воскрешение процесс длительный и постепенный. Согласно Федорову, победа над смертью может свершиться только при сложении творческих усилий и труда всего Человечества, которое, преодолевая болезни и смерть, движется к Бессмертию [13]. Эта теория была близка творческой интеллигенции Серебряного века: В. Брюсову, В. Маяковскому, В. Хлебникову, М. Пришвину, А. Платонову, Б. Пастернаку.

Другой выдающийся русский философ, Владимир Сергеевич Соловьев, в статье «Идея сверхчеловека» развивает мысль Федорова о преодолении смерти. Говоря о господствующих в современном мире трех модных идеях: «Маркс, Лев Толстой, Фридрих Ницше» - третью идею Соловьев называет «самою интересною» $[11,611]$. На ницшеанство, считает он, нужно посмотреть «с хорошей стороны» $[11,612]$ : в понятии «сверхчеловек» можно услышать не только «голос ограниченного и пустого притязания», но и голос, «предваряющий бесконечную будущность» $[11,612-613]$. Человеческая форма может беспредельно совершенствоваться - и это путь к преодолению смерти.

Подобный подход к идее будущего воскрешения оспорил Н. Федоров в статье «Бессмертие, как привилегия сверхчеловеков. (По поводу статьи В. С. Соловьева о Лермонтове)». Согласно В. Соловьеву, к «бесконечной будущности» подготовлен только «сверхчеловек». Все умершие, утверждает Н. Федоров, должны быть возвращены «любовью и знанием всех потомков» $[12,139]$. Лермонтов, которого В. Соловьев относит к «сверхчеловекам», «не понял бы бессмертия сынов без воскрешения отцов» $[12,139]$. «Сверхчеловечество бессмертное, 
в соловьевском смысле, как превозношение над своими предками и отцами и современниками или братьями, гораздо более безнравственно, чем превозношение богатством и властью, какое мы видим в нашей немифической, секулярной жизни», - утверждает Н. Федоров [12, 138].

Мотив воскрешения не единожды возникает в творчестве Леонида Андреева. Рассказ «Прекрасна жизнь для воскресших» (1900), «лирический набросок, близкий к стихотворению в прозе» ${ }^{1}$ был написан под впечатлением посещения «города мертвецов», Ваганьковского кладбища, куда перенесен «весь живой, огромный и шумный город». Лирический герой потрясен вдруг пришедшим осознанием неизбежности ухода: «Видите вы их молодыми, смеющимися, любящими; <...> дерзко уверенными в бесконечности жизни» $(1,193)$. Кладбищем, «маленьким, жадным и так много поглотившим», на котором покоятся надежды, любовь, талант, видится ему и душа человеческая:

Пусть же воскреснут мертвецы! Раскройтесь, угрюмые могилы, разрушьтесь вы, тяжелые памятники, и расступитесь, о железные решетки!

Хоть на день один, хоть на миг один дайте свободу тем, кого вы душите своей тяжестью и тьмой! $(1,194)$.

В спор с Н. Федоровым, Ф. Достоевским, которому также были близки идеи философа, В. Соловьевым и самим собой, провозгласившим когда-то: «Прекрасна жизнь для воскресших!», - Л. Андреев вступает в 1903 году в рассказе «Жизнь Василия Фивейского». Мотив возмущения против Бога, равнодушного к людским страданиям, звучащий во многих произведениях Л. Андреева, исследователи справедливо ведут от Л. Толстого. Ужас «молчащего Ничто, подчиняющего себе человека» [7, 345], охватывает как усомнившегося в божественной справедливости Ивана Ильича («Смерть Ивана Ильича» Л. Толстого), так и Василия Фивейского.

О «Жизни Василия Фивейского» критик Волжский писал, что рассказ Андреева «бередит всех», это «мучительное боление Богом, это страстная религиозная тревога» [3]. Рассказ высоко оценил М. Горький. В. Г. Короленко суть рассказа понял 
как «вечный вопрос человеческого духа в его искании своей связи с бесконечностию вообще и с бесконечной справедливостью в частности» [8]. А. Блок, по его признанию, испытал потрясение при чтении этого андреевского рассказа, видел в нем, как позже и в драме «Жизнь Человека», предчувствие катастрофы $[2,56]$.

Современники Андреева и исследователи более позднего времени видели в рассказе прежде всего поиск ответов "на феномен “человекобожества", <..> вступая в новое соприкосновение с Достоевским и Ницше» [7, 392]. В этом произведении они находили житийное начало и авторское переложение Книги Иова, в которой «с необычной остротой поставлены вопросы о цели человеческого бытия, о границах человеческого разума в их соотнесении с божественным провидением» $[6,103]$. В отличие от Иова, верящего в непогрешимость Божьего Промысла, Василий Фивейский верит иначе: для него Бог - это идея о гармоничном, разумном и справедливом мироустройстве. А поскольку реальность убеждает его в непреходящем характере несправедливости и страданий, вера священника обретает иную, не соответствующую церковным догматам направленность. Как пишет Л. А. Иезуитова, «о. Василий делается “святым”, пройдя мученическую жизнь, через познание страданий и грехов человеческих» $[6,103]$.

«Соприкосновение» между Андреевым и Федоровым / Coловьевым в осмыслении проблемы «победы над смертью» осталось за пределами внимания исследователей. А между тем история священника, до трагических событий в своей жизни верящего в Бога «торжественно и просто: как иерей и как человек с незлобивой душою» $(1,489)$, а затем проникшегося идеей собственной избранности, дающей ему право, вслед за подвигом Христа, совершить свой подвиг - воскресить страдальца и праведника при жизни Семена Мосягина, это отклик и на «Философию общего дела» Н. Федорова, и на «Идею сверхчеловека» В. Соловьева.

Вера в свою избранность - это вызов року, властвовавшему над жизнью Василия Фивейского, отобравшему у него любимого сына, «черненького и тихонького» Васю, а взамен 
давшему «нового Васю». Рождение идиота, первый вариант «воскрешения» в рассказе, - псевдовоскрешение. «Господство над домом» - так определена роль идиота в «схеме жизни Василия Фивейского» (см. об этом: $[9,40])$. И эта власть безумия над миром, над всеми людьми заставляет задуматься о нравственных последствиях возвращения из небытия, что, однако, не останавливает о. Василия от попытки нового воскрешения: поверив в свое избранничество, он обращается к разлагающемуся телу Семена Мосягина: «Тебе говорю, встань!» $(1,551)$.

Всесилие рока касается только телесной оболочки человека, обреченного на смерть, но дух его свободен, и никто не в состоянии остановить его прорыва к «метафизической тайне». Зародившиеся сомнения в любви идеальной - к Богу, приводят героя к любви реальной - к людям. Ранее существовавшая между о. Василием и его прихожанами пропасть преодолевается, к священнику приходит понимание людских страданий. Откровения прихожан потрясают его своей простотой и правдой, сострадание и отчаяние оттого, что он, служитель Бога на земле, ничем не может им помочь, рождают святую веру: через него, избранника, Бог должен сотворить чудо. Нелепая и страшная гибель Семена Мосягина, молодого мужика, труженика, кормильца большого семейства, должна явить возможность «преодоления смерти», возвращения из небытия.

Герой повести «почитает того Бога, который даст человеку - в его, Фивейского, лице - власть над “жизнью и смертью”. Иначе говоря, безгранично, вровень с собою, возвысит личность $<\ldots .>$. Но попытки найти себя в Боге (точнее, в метафизической тайне, которая здесь, в рассказе о священнике, предстает под именем “Бог”) кончаются крахом. Чаемое горнее благо обернулось инфернальной злобою, поправшей мученическую жизнь, но не смогшей унизить ее» [7, 393].

В тексте, который наполнен мифологическим, религиознофилософским и даже фантастическим материалом, в особо концентрированном виде проявляются «онтологические проблемы бытия, фундаментальные принципы устройства мира и человека, достигается модус сопряжения национального 
с универсальным» $[10,91]$. При этом писатель предлагает неожиданную интерпретацию традиционных сюжетов и образов, переосмысляя евангельскую историю, рассматривая ее в ином, неклассическом, ракурсе.

Примечателен в этом плане рассказ Андреева «Елеазар» (1906), в основе которого также лежит евангельский сюжет о воскрешении Христом Лазаря (см. об этом: [5]). Центром евангельского сюжета становится чудо, совершенное Спасителем; судьба самого Лазаря, его дальнейшая жизнь не попадает в фокус повествования. Андреева же интересует сам воскресший, то, что увидел он по ту сторону человеческого бытия, и то, каким он стал после обретения нового знания. Философской темой произведения становится вопрос: возможна ли жизнь в полном смысле этого слова для человека, видевшего смерть и ее преодолевшего, прикоснувшегося к тайне, к «грозному ужасу Бесконечного»? $(2,207)$.

Пространственно-временные координаты, заданные в «Елеазаре», соответствуют евангельскому хронотопу: у самого порога дома воскресшего - великая пустыня, «холодная, жадно рыскающая», в которой днем царствует беспощадное солнце «убийца всего живого», а ночью - «великая тьма» $(2,196,198)$. Пустыня - пространство, лишенное жизни, и это есть воплощение смерти. У Андреева такой пейзаж символически изображает жизнь Елеазара после воскресения; это «жизнь-всмерти», объятая холодом и мраком, это и опыт познания смерти, после которого возможна лишь «великая пустота».

Образ пустыни в рассказе не имеет традиционного христианского значения - не воспринимается как место испытания веры и очищения и одновременно близости к Богу, но все же связан с мотивом духовного поиска, стремления познать что-то за гранью реальной действительности. Андреевский Елеазар каждый вечер во время заката уходит вглубь пустыни, вслед за солнцем, как будто пытаясь поймать уходящую жизнь и ее тепло, ибо после таинственного возвращения из смерти в нем нет жизни, есть только «холод трехдневной могилы» $(2,197)$. Мотив поиска смысла жизни в рассказе связан, скорее, с фигурой Августа, который воплощает силу «духа, помогающего человеку выстоять перед лицом Вечности» $[10,96]$. 
В рассказе Андреева время тоже «перестает быть потоком, <...> а становится неподвижным измерением - тем, что для нас теперь пространство» [4, 50-51]. Елеазар, время для которого когда-то остановилось, а потом повернуло вспять, сливается с окружающим его пейзажем (пустыня, «тяжелая чернота ночи», дуновение холодного ветра) и представляется через пространственные образы: с ним связано ощущение великой тьмы и великой пустоты мироздания. Взгляд Елеазара «бесконечно равнодушен к живому», как будто страшную тень он опускает на души людей и новый облик дает «старому знакомому миру» $(2,197)$. От взгляда героя земную жизнь поглощает «черная утроба Бесконечного», течение времени останавливается, а «начало каждой вещи» сближается «с концом ее» $(2,208)$.

Воскресение Лазаря, воспетое Евангелием, представлено Андреевым как трагедия и самого воскресшего, и всех тех, с кем он соприкасается в своей «второй жизни». Воскресший вызывает лишь страх и проклятие окружающих, на все распространяется мертвенный свет, который он принес из Бесконечности. «Печальной и сумрачной» становилась жизнь людей, когда на них падал «загадочный», тяжелый и страшный взгляд Елеазара, из которого смотрело «само непостижимое Там» $(2,196)$. Его присутствие ослабляло волю к жизни, мир терял свои яркие краски, переставал радовать и виделся человеку объятым великой пустотой. В рассказе есть некий зримый аналог душевного хаоса Елиазара: это последняя скульптура великого Аврелия, представляющая собой «нечто чудовищное, не имевшее в себе ни одной из знакомых глазу форм, но не лишенное намека на какой-то новый, неведомый образ», это «слепая, безобразная, раскоряченная груда чего-то ввернутого внутрь, чего-то вывернутого наружу, каких-то диких обрывков, бессильно стремящихся уйти от самих себя» $(2,201)$. Скульптура становится иллюстрацией к теме поиска смысла за пределами жизни, символизирует бесплодность попыток постичь мир, отрицая смерть.

Пространство произведения построено на контрасте жизни земной (древний город пестрит цветами и счастливыми людьми, влюбленными парами) и неземной (пещера, куда погребли Елеазара, и место его вечного изгнания - пустыня). Очевидно одно: там, где отметилась вечность, пространство бесконечно 
расширяется под ее давлением. Непрекращающееся время создает такое же непрерывное пространство, которое вынуждено продолжаться.

Получив вначале пространственное воплощение, идея вечной жизни содержательно раскрывается в третьей части рассказа: это пустое, лишенное морально-нравственных основ существование, в котором «объятый пустотой и мраком безнадежно трепетал человек перед ужасом бесконечного» $(2,198)$. Бесконечное время такой жизни лишено логики, морали, этики, ибо любые поступки, благородные и добродетельные, лживые и предательские, в ней возможны и неизбежны. Абсурд и ужас «жизни в бессмертии» передается иррациональными, странными, мрачно-гротескными пространственными образами.

Основная задача писателя - психологически обосновать характер героя, который, пообщавшись с Бесконечностью, перестал воспринимать земную жизнь так, как обычные люди: он фактически перестал быть человеком. Авторский миф требует особых средств художественного воплощения. По словам И. Анненского, Андреева «замучили контуры, светотени, контрасты, сгущение теней и беспокойные пятна», и «все эти животности, часто не только не оскорбительные, но даже не приметные для нашего тупого и рассеянного восприятия, накопляясь в нежной душе художника, создали там муку, безобразие и неразрешимость...» $[1,556]$.

Главенствующий в рассказе лексический прием - контраст. Воскресший мертвец «с лицом трупа», выписанным натуралистически подробно (прав М. Волошин, когда говорит об андреевском «анатомическом театре» $[4,48])$, - и «пышные брачные одежды» на нем; «прекрасное гордое лицо» скульптора и страшное, отталкивающее лицо Елеазара; «дико кричащие выступы» бесформенной скульптуры Аврелия, которую он создал под впечатлением встречи с живым мертвецом, - и «дивно изваянная» им же бабочка. Эти противоположности, казалось бы, несовместимы, но волею Христа, нарушившего извечно действующий закон о смерти, которую «знал только мертвый, а живой знал только жизнь» $(2,206)$, сделавшего попытку стереть грань между бытием и небытием, - сосуществуют, как ни противоестественно, ни антигуманно их сосуществование. 
Задачу усиления контраста выполняют в рассказе и антонимы: прекрасный - безобразный, поцелуи - слезы, наслаждение - боль, правда - ложь... Экспрессивно насыщенными оказываются у Андреева разные части речи: глаголы - низвергать, разрушать, воздвигать, вздымать; наречия - безумно, бессильно, тупо, безнадежно. Частое употребление местоименных форм, особенно неопределенных местоимений, придает повествованию оттенок загадочности, нагнетает атмосферу страха: «Кто-то неосторожный приподнял покрывало. Кто-то неосторожным одним дуновением брошенного слова разрушил светлые чары и в безобразной наготе открыл истину» $(2,193)$.

«Нагнетание ужасов» происходит и через экспрессивно окрашенную деталь: «густая землистая синева» на лице Елеазара, «так же землисто-сини были длинные пальцы рук». Люди испытывали «губительную силу его взора». Попавший под его взгляд человек "уже не чувствовал солнца», «не слышал фонтана и не узнавал родного неба», и человек «равнодушно и спокойно» «начинал умирать, и умирал он долгими годами, умирал на глазах у всех...» $(2,192-195)$.

Все сказанное подтверждает мысль о том, что писатель не принимает идею времени, не имеющего конца. Время - великий регулятор человеческих отношений и поступков, чувств и мыслей, и тот, кто его не ощущает, лишен смысла и цели существования, живет под знаком «смерти в жизни».

Опыт преодоления смерти в произведениях Андреева ужасает больше, чем неотвратимость смерти, которая и в случае с Василием Фивейским, и с Елеазаром оказывается желанной наградой. Андреев развенчивает миф о Лазаре и о Царствии Божием, о гармонии и порядке, которые должны главенствовать в этом центре мироздания. Мысль о том, что продлевать жизнь человеческую до бесконечности означает продлевать агонию и заставлять человека умирать множество раз, вполне соответствует идее андреевского рассказа. Именно понимание конечности времени, память о смерти помогают сохранять свежесть чувства и мысли, жить в рамках морально-нравственных категорий, наслаждаться каждым мгновением земной жизни. 


\section{Примечания}

1 Андреев Л. Н. Собр. соч.: в 6 т. М.: Худож. лит., 1990. Т. 1: Рассказы 1898-1903. С. 597. Далее ссылки на издание приводятся в тексте статьи с указанием тома и страницы в круглых скобках.

\section{Список литературы}

1. Анненский И. Ф. Вторая книга отражений. Иуда, новый символ // Избранные произведения. - Л.: Худож. лит., 1988. - С. 549-554.

2. Книга о Леониде Андрееве: воспоминания М. Горького, К. Чуковского, А. Блока, Г. Чулкова, Б. Зайцева, Н. Телешова, Е. Замятина. - Пб.; Берлин: Изд. З. И. Гржебина, 1922. - 111 с.

3. Волжский. Литературные письма. О голосах критики по поводу «Жизни Василия Фивейского» Леонида Андреева // Голос юга. - 1904. 14 дек. - (№ 9).

4. Волошин М. А. «Елеазар», рассказ Леонида Андреева («Золотое Руно») // Волошин М. А. Собр. соч.: в 13 т. (в 17 кн.). - М.: Эллис Лак, 2007. Т. 6. - Кн. 1: Проза 1906-1916. Очерки, статьи, рецензии. - С. 43-53 [Электронный ресурc]. — URL: http://imwerden.de/pdf/voloshin_sobranie_ tom06.1_2007_text.pdf

5. Иезуитова Л. А. «Елеазар», библейский рассказ Л. Н. Андреева // Блоковский сборник XIII (Памяти В. И. Беззубова): Русская культура XX века: метрополия и диаспора. - Тарту: Tartu Ülikooli Kirjastus, 1996. - С. 39-62.

6. Иезуитова Л. А. Жизнь Василия Фивейского // Иезуитова Л. А. Леонид Андреев и литература Серебряного века: Избранные труды. - СПб.: Петрополис, 2010. - С. 97-135.

7. Келдыш В. А. О «серебряном веке» русской литературы. Общие закономерности. Проблемы прозы. - М.: ИМЛИ РАН, 2010. - 511 с.

8. Короленко В. Г. О сборниках товарищества «Знание» за 1903 год // Русское богатство. - 1904. - № 8 [Электронный ресурс]. - URL: http:// az.lib.ru/k/korolenko_w_g/text_1903_znanie_oldorfo.shtml.

9. Михеичева Е. А. О психологизме Леонида Андреева. - М.: Московский педагог. университет, 1994. - 189 с.

10. Московкина И. И. Поэтика легенд и притч Л. Андреева // Поэтика жанров русской и советской литературы: межвуз. сб. науч. тр. - Вологда, 1988. - С. 86-102.

11. Соловьев В. С. Идея сверхчеловека // Соловьев В. С. Сочинения: в 2 т. М.: Правда, 1989. - Т. 2: Чтения о богочеловечестве. Философская публицистика. - С. 610-618.

12. Федоров Н. Ф. Бессмертие, как привилегия сверхчеловеков. (По поводу статьи В. С. Соловьева о Лермонтове) // Федоров Н. Ф. Собр. соч.: в 4 т. - М.: Издательская группа «Прогресс», 1995. - Т. 2. - С. 136-140 [Электронный ресурc]. — URL: http://www.magister.msk.ru/library/philos/ fedorov/fedor072.htm.

13. Федоров Н. Ф. Статьи религиозного содержания из III тома «Философии общего дела» // Федоров Н. Ф. Собр. соч.: в 4 т. - М.: Традиция, 1997. - T. 3. - C. 391-448. 


\title{
Ekaterina A. Mikheicheva
}

\section{RESURRECTION MOTIF IN THE WORKS OF LEONID ANDREEV}

\begin{abstract}
This article is devoted to the problem of resurrection which was widely spread in Silver age philosophy and literature. Basing on the New Testament, Russian philosophers N. Fyodorov and V. Solovyov associated the resurrection process with improvement of the nature and unification of the humankind. Leonid Andreev saw the consequences of returning from the nothingness to the real world in a different way. The attempts of resurrection (Vasily Fiveisky) and the resurrection itself (Eleasar) were seen by him as a tragedy of the personality. Fiveisky who believed to be the God's elect did not manage to repeat the miracle of Jesus - to resurrect Semion Mosyagin, and that became the reason for the character's madness and death. The resurrection of Lasarus, who saw death and overcame it, is represented by Andreev as a tragedy for both the resurrected and all the people he came in contact with after his returning from the beyond. The notion of a time limit and its understanding help people keep the freshness of their feelings and thoughts, to limit their lives by the moral categories, to enjoy every moment of their secular life.
\end{abstract}

Keywords: philosophy, literature, New Testament, Leonid Andreev, resurrection motif, time, space, tragedy

\section{References}

1. Annenskiy I. F. The Second Book of the Reflections. Judah, New Symbol. In: Izbrannye proizvedeniya [Selected Works]. Leningrad, Khudozhestvennaya literatura Publ., 1988, pp. 549-554. (In Russ.)

2. Kniga o Leonide Andreeve. Vospominaniya M. Gor'kogo, K. Chukovskogo, A. Bloka, G. Chulkova, B. Zaytseva, N. Teleshova, E. Zamyatina [The Book About L. Andreev. The Recollections of M. Gorky, K. Chukovsky, A. Block, G. Chulkov, Boris Zaitsev, N. Teleshov, E. Zamyatin]. Petersburg, Berlin, Izdatel'stvo Z. I. Gzhebina, 1922. 109 p. (In Russ.)

3. Volzhskiy. Literary Letters. About Critical Voices on "Life of Vasily Fiveisky" by L. Andreev. In: Golos yuga, 1904, 14 dec., no. 9. (In Russ.)

4. Voloshin M. A. "Eleasar", L. Andreev's Short Story ("Zolotoe Runo"). In: Voloshin M. A. Sobranie sochineniy: $v 13$ tomakh (v 17 knigakh) [Voloshin M. A. Collected Works: in 13 Vols (in 17 Books)]. Moscow, Ellis Lak Publ., 2007, vol. 6, book 1: Prose 1906-1916. Essays, Articles, Reviews, pp. 43-53. Available at: http://dugward.ru/library/voloshin/voloshin_eleazar.html. (In Russ.)

5. Iezuitova L. A. "Eleasar", L. Andreev's Biblical Short Story. In: Blokovskiy sbornik XIII: Pamyati V. I. Bezzubova: Russkaya kul'tura XX veka: metropoliya i diaspora [The 13th Blok Digest: The Mother Country and an Expat Community]. Tartu, Tartu Ülikooli Kirjastus Publ., 1996, pp. 39-62. (In Russ.) 
6. Iezuitova L. A. "Life of Vasily Fiveisky". In: L. A. Iezuitova. Leonid Andreev $i$ literatura serebryanogo veka: Izbrannye trudy [L. A. Iezuitova. Leonid Andreev and Literature of the Silver Age: Selected Works]. St. Petersburg, Petropolis Publ., 2010, pp. 97-135. (In Russ.)

7. Keldysh V. A. O «serebryanom veke» russkoy literatury. Obshchie zakonomernosti. Problemy prozy [About the Silver Age of Russian Literature. Common Factors. Problems of Prose]. Moscow, A. M. Gorky Institute of World Literature of the Russian Academy of Sciences Publ., 2010. 511 p. (In Russ.)

8. Korolenko V. G. About Collections of Partnership Association "Knowledge" of 1903. In: Russkoe bogatstvo, 1904, no. 8. Available at: http://az.lib.ru/k/ korolenko_w_g/text_1903_znanie_oldorfo.shtml. (In Russ.)

9. Mikheicheva E. A. O psikhologizme Leonida Andreeva [About L. Andreev's Psychologism]. Moscow, Moscow State Pedagogical University Publ., 1994. 189 p. (In Russ.)

10. Moskovkina I. I. The Poetics of Legends and Parables of L. Andreev. In: Poetika zhanrov russkoy i sovetskoy literatury: Mezhvuzovskiy sbornik nauchnykh trudov [The Poetics of Genres of Russian and Soviet Literature: Interuniversity Collection of Scientific Papers]. Vologda, 1988, pp. 86-102. (In Russ.)

11. Solov'ev V. S. The Idea of the Overman. In: Solovev V. S. Sochineniya: $v 2$ tomakh [Solovyov V. S. Works: in 2 Vols]. Moscow, Pravda Publ., 1989, vol. 2: Readings About God-Mankind. Philosophical Journalism, pp. 610-618. (In Russ.)

12. Fedorov N. F. Immortality as a Privilege of the Overmen. On V. Solovyov's Article About Lermontov. In: Fedorov N. F. Sobranie sochineniy: $v 4$ tomakh [Fyodorov N. F. Collected Works: in 4 Vols]. Moscow, "Progress" Publ., 1995, vol. 2, pp. 136-140. Available at: http://www.magister.msk.ru/library/philos/ fedorov/fedor072.htm. (In Russ.)

13. Fedorov N. F. Religious Articles of the Third Volume of "Philosophy of the Common Goal". In: Fedorov N. F. Sobranie sochineniy: $v 4$ tomakh [Fyodorov N. F. Collected Works: in 4 Vols]. Moscow, Traditsiya Publ., vol. 3, 1997, pp. 391-448. (In Russ.) 